\title{
Whole genome analysis of linezolid resistance in Streptococcus pneumoniae reveals resistance and compensatory mutations
}

\author{
Dewan S Billal', Jie Feng ${ }^{1,2}$, Philippe Leprohon ${ }^{1}$, Danielle Légaré ${ }^{1}$ and Marc Ouellette
}

\begin{abstract}
Background: Several mutations were present in the genome of Streptococcus pneumoniae linezolid-resistant strains but the role of several of these mutations had not been experimentally tested. To analyze the role of these mutations, we reconstituted resistance by serial whole genome transformation of a novel resistant isolate into two strains with sensitive background. We sequenced the parent mutant and two independent transformants exhibiting similar minimum inhibitory concentration to linezolid.

Results: Comparative genomic analyses revealed that transformants acquired G2576T transversions in every gene copy of $23 \mathrm{~S}$ rRNA and that the number of altered copies correlated with the level of linezolid resistance and crossresistance to florfenicol and chloramphenicol. One of the transformants also acquired a mutation present in the parent mutant leading to the overexpression of an ABC transporter (spr1021). The acquisition of these mutations conferred a fitness cost however, which was further enhanced by the acquisition of a mutation in a RNA methyltransferase implicated in resistance. Interestingly, the fitness of the transformants could be restored in part by the acquisition of altered copies of the L3 and L16 ribosomal proteins and by mutations leading to the overexpression of the spr1887 ABC transporter that were present in the original linezolid-resistant mutant.

Conclusions: Our results demonstrate the usefulness of whole genome approaches at detecting major determinants of resistance as well as compensatory mutations that alleviate the fitness cost associated with resistance.
\end{abstract}

\section{Background}

Streptococcus pneumoniae is a Gram-positive pathogen responsible for serious diseases such as pneumonia, meningitis, acute otitis media and sepsis. Although vaccination campaigns have been useful at decreasing the prevalence of the most frequent serotypes, the appearance and spread of drug-resistant isolates not included in the initial vaccine formulations are now threatening our capacity at dealing with these infections [1]. The increase in resistance to several classes of antimicrobials due to the clonal spread of few multidrug resistant isolates further worsens the situation. Fortunately, surveillance studies revealed that every strains of $S$. pneumoniae tested were sensitive to linezolid (LNZ) [2-5], the first approved member of the oxazolidinone

\footnotetext{
* Correspondence: Marc.Ouellette@crchul.ulaval.ca

Full list of author information is available at the end of the article
}

class of antibiotics. LNZ inhibits the formation of protein synthesis initiation complexes by binding to the central loop segment of domain $\mathrm{V}$ of the 23S rRNA [6]. Recent cross-linking and crystallography experiments further revealed that LNZ binds near the catalytic center of the 50S ribosomal subunit and possibly interferes with the placement of the aminoacyl-tRNA [7,8]. LNZ is highly effective against a number of clinically important gram-positive pathogens like Staphylococcus aureus and its methicillin-resistant version (MRSA), enterococci and their vancomycin-resistant versions (VRE), and S. pneumoniae [9]. Still, S. pneumoniae and Streptococcus oralis isolates with reduced susceptibility to linezolid (MIC 4 $\mu \mathrm{g} / \mathrm{ml})$ have been already reported $[10,11]$ and the emergence of resistance is unfortunately likely.

Resistance to linezolid in gram-positive bacteria was shown to be associated with key mutations in the domain $\mathrm{V}$ of $23 \mathrm{~S}$ rRNA or in the ribosomal proteins L3
() Biomed Central

() 2011 Billal et al; licensee BioMed Central Ltd. This is an Open Access article distributed under the terms of the Creative Commons Attribution License (http://creativecommons.org/licenses/by/2.0), which permits unrestricted use, distribution, and reproduction in any medium, provided the original work is properly cited. 
and L4 [12,13]. Although several mutations have been pinpointed, the G2576T transversion in 23S rRNA (when using the $E$. coli numbering system) is the most frequently observed [14] and was shown to occur in clinical isolates of $S$. aureus $[13,15]$, S. epidermidis [16-18], S. hominis [18], S. simulans [18] and in Enterococci [19-21] resistant to linezolid. There are four to six gene copies of $23 \mathrm{~S}$ rRNA in most gram-positive pathogens, and the level of LNZ resistance as well as the fitness cost usually correlates with the number of mutated copies [22-26]. The domain V of $23 \mathrm{~S}$ rRNA is the binding site of other translation inhibitors like chloramphenicol, florfenicol and quinupristin-dalfopristin, and the G2576T mutation was shown to confer cross-resistance to these antibiotics. A six base pair deletion in the ribosomal protein L4 of S. pneumoniae isolates resistant to chloramphenicol was also shown to be associated with non-susceptibility to LNZ [10], and mutations in ribosomal proteins L3 [18,27,28], L4 [18,27,29-31] and L22 $[2,18]$ were further observed in other LNZ-resistant gram-positive bacteria. High levels of resistance to LNZ were shown to be conferred by a plasmid-borne methyltransferase (Cfr) involved in ribosomal protection [32] and recent outbreaks of LNZ-resistant S. epidermidis and $S$. aureus have been associated with the clonal spread of Cfr-containing strains [33-35].

Whole genome sequencing of laboratory generated LNZ-resistant $S$. pneumoniae recently revealed mutations in several genes, three of which (a chromosomallyencoded methyltransferase and two ABC transporters) were implicated in resistance to LNZ [29]. Several other mutations were not studied. To improve our understanding of the role of these mutations in LNZ resistance, we used a whole genome transformation approach to reconstruct resistance. DNA extracted from LNZ-resistant mutants was serially transformed in sensitive isolates and the genomes of these transformants were sequenced. We found that the selection of LNZ resistance is accompanied by the acquisition of resistance determinants that confer a fitness cost and of compensatory mutations that partially alleviates the growth defect of the resistant strains.

\section{Results}

The genome sequence of three independent in vitroselected LNZ-resistant S. pneumoniae mutants (R6M1, R6M2 and 1974M2) previously revealed the presence of several mutations [29], but the role in resistance had only been studied for some of these. For a more global understanding of the genetic variations associated with resistance to $L N Z$, we studied a new resistant strain named 1974M1 (LNZ MIC, $32 \mu \mathrm{g} / \mathrm{ml}$ ). The transformation of high molecular weight DNA extracted from 1974M1 into S. pneumoniae sensitive strains followed by the selection of the transformants under LNZ pressure should allow discriminating the mutations actually involved in resistance from bystander mutations that may have been randomly selected during the selection process. A total of three rounds of transformation of 1974M1 genomic DNA were required to fully reconstruct the high level LNZ resistance of 1974M1 into the S. pneumoniae 1974 background (leading to the transformant 1974T3) (Table 1, Additional File 1). We also used a similar strategy of transforming the genomic DNA of 1974M1 into the R6 strain but despite several attempts we could not reach a LNZ MIC higher than 16 $\mu \mathrm{g} / \mathrm{ml}$ (leading to the transformant R6T2) (Table 1, Additional file 1). Considering the higher initial LNZ MIC of 1974 compared to R6, the fold-increase in resistance was the same between the last two transformants (Table 1).

In order to identify the mutations that had been transferred to 1974T3 and R6T2, the genome sequences of the parent mutant $1974 \mathrm{M} 1$ and of both transformants were determined by 454 pyrosequencing. More than $97 \%$ of the reads of $1974 \mathrm{M} 1, \mathrm{R} 6 \mathrm{~T} 2$ and $1974 \mathrm{~T} 3$ assembled into 90 to 115 large contigs covering more than $98 \%$ of the genome with mean depth coverage of 20X. While we cannot exclude having missed some point mutations, we were capable of fully reconstructing resistance using both a whole genome approach (Table 1) and a targeted approach (see below). Of the fifteen mutations identified in the 1974M1 mutant (Table 2), six mutations were transferred into both $1974 \mathrm{~T} 3$ and R6T2 transformants (Table 2). These included the G2576T transversion observed in the four copies of the 23S rRNA and missense mutations in the L3 and L16 ribosomal proteins. The only other $1974 \mathrm{M} 1$ mutation to be transferred was a $\mathrm{G}$ to $\mathrm{T}$ transversion that specifically occurred 29 nucleotides upstream of the start codon of spr1021 in the 1974T3 transformant (Table 1). No spontaneous mutations occurred during the selection of the transformant bacteria.

The targeted sequencing of transformants isolated at different rounds of transformation (R6T1, R6T2 and $1974 \mathrm{~T} 1$ to $1974 \mathrm{~T} 3)$ revealed that the acquisition of mutations in 23S rRNA began during the first round of transformation in both R6 and 1974 genetic backgrounds while the mutations in the L3 and L16 ribosomal proteins or upstream of spr1021 only occurred during the second and third rounds of transformation (Table 1). The acquisition of mutations in the $23 \mathrm{~S}$ rRNA is a well established LNZ resistance determinant and the serial transformation of mutated 23S rRNA gene copies also translated into a stepwise increase in LNZ resistance in S. pneumoniae R6 in addition to increase cross-resistance to chloramphenicol and florfenicol but not to penicillin (Table 3). We were never able 
Table 1 Chronological appearance of mutations in S. pneumoniae R6 and 1974 transformants at different levels of linezolid resistance ${ }^{a}$.

\begin{tabular}{|c|c|c|c|c|c|c|c|c|c|}
\hline $\begin{array}{l}\text { S. pneumoniae strains/ } \\
\text { transformants }^{b, c}\end{array}$ & $\begin{array}{l}\text { LNZ MIC } \\
(\mu \mathrm{g} / \mathrm{ml})\end{array}$ & $\begin{array}{l}\text { No. of colonies } \\
\text { tested }\end{array}$ & $\begin{array}{l}\text { spr }_{-} \\
\text {rrnaD }\end{array}$ & $\begin{array}{l}\text { spr }_{-} \\
\text {rrnaC }^{\text {d }}\end{array}$ & $\begin{array}{l}\text { spr }_{-} \\
\text {rrnaB }^{d}\end{array}$ & $\begin{array}{l}\text { spr_- }_{\text {rrnaA }} \\
\text { ref }^{2}\end{array}$ & spr0188 & spr0196 ${ }^{f}$ & spr1021 \\
\hline R6 & 0.5 & 4 & W & W & W & W & W & W & W \\
\hline R6T1 & 8 & 4 & $M$ & W & W & $M$ & W & W & W \\
\hline R6T2 & 16 & 4 & $M$ & $M$ & M & M & $M$ & $M$ & W \\
\hline 1974 & 1 & 4 & W & W & W & W & W & W & W \\
\hline 1974T1 & 8 & 4 & $M$ & $M$ & M & W & W & W & W \\
\hline 1974T2 & 16 & 4 & $M$ & $M$ & M & W & W & W & W \\
\hline 1974T3 & 32 & 4 & $M$ & $M$ & $M$ & $M$ & $M$ & $M$ & $M$ \\
\hline
\end{tabular}

${ }^{\mathrm{a}} \mathrm{W}$ (wild-type version); M (1974M1 version).

${ }^{b}$ R6T1 and R6T2 are first and second level transformants, respectively, of S. pneumoniae R6 transformed with genomic DNA extracted from $1974 \mathrm{M} 1$.

'1974T1, 1974T2 and 1974T3 are first, second and third level transformants, respectively, of S. pneumoniae 1974 transformed with genomic DNA extracted from $1974 \mathrm{M} 1$.

d Mutant 1974M1 had a G2576T mutation in the four copies of spr_rrna23S.

e Mutant 1974M1 had a T409C mutation in spr0188.

${ }^{f}$ Mutant 1974M1 had a A235G mutation in spr0196.

${ }^{g}$ Mutant 1974M1 had a G-29T mutation in spr1021 (the number preceded by ' - ' indicates the position upstream of the ATG).

to select for unique integration events of the G2576T mutation in the 1974 background however, as it was always acquired by the four copies of $23 \mathrm{~S}$ rRNA at the same time (Table 3). Nonetheless, this led to similar fold increase in LNZ resistance than in S. pneumoniae R6 (Table 3) and was also linked to chloramphenicol and florfenicol cross-resistance (Table 3). The missense mutations in the $50 \mathrm{~S}$ ribosomal proteins L3 (spr0188) and L16 (spr0196) of 1974M1 appear to require a specific genetic background for resistance as they were only able to decrease LNZ susceptibility when transformed into a strain in which the four copies of 23S rRNA were mutated (named T-7) (Table 4) and not when transformed into WT strains of S. pneumoniae R6 (Table 4) or 1974 (data not shown).

The 23S rRNA genes and the rRNA methyltransferase spr0333 were the only mutated genes common to 1974M1 and three other S. pneumoniae LNZ-resistant strains described previously [29] (Figure 1). The only other mutations acquired in common by $1974 \mathrm{M} 1$ and at least one of these other mutants were a $\mathrm{G}$ to $\mathrm{T}$ transversion in the promoter regions of the ATP-binding

Table 2 Common mutations found between the S. pneumoniae 1974M1 mutant and the transformants resistant to linezolid.

\begin{tabular}{|c|c|c|c|c|}
\hline Name/function of genes & Locus Name $^{a}$ & $1974 M 1^{b, c}$ & T-1974T3 $3^{b, c, d}$ & T-R6T2 $2^{\text {b,e }}$ \\
\hline $23 S$ rDNA & spr_rrnaD23S & G2576T & G2576T & G2576T \\
\hline 235 rDNA & spr_rrnaC23S & G2576T & G2576T & G2576T \\
\hline 235 rDNA & spr_rrnaB23S & G2576T & G2576T & G2576T \\
\hline 235 rDNA & spr_rrnaA23S & G2576T & G2576T & G2576T \\
\hline $50 S$ ribosomal protein L3 & spr0188 & $\mathrm{T} 409 \mathrm{C} \mathrm{Y137H}$ & $\mathrm{T} 409 \mathrm{C}$ Y137H & $\mathrm{T} 409 \mathrm{C} \mathrm{Y137H}$ \\
\hline 50 S ribosomal protein L16 & spr0196 & A235G $179 L$ & A235G I79L & A235G I79L \\
\hline ABC transporter ATP-binding subunit & spr1021 & G-29T & G-29T & \\
\hline Conserved hypothetical/rRNA methyltransferase & spr0333 & G503T S1681 & & \\
\hline Sodium/hydrogen exchanger family protein & spr0573 & G141A T47I & & \\
\hline Conserved hypothetical protein & spr0855 & G25A A9T & & \\
\hline Fibronectin-binding protein-like protein A & spr0868 & C617A S2061 & & \\
\hline Conserved hypothetical protein & spr1115 & C29T T10l & & \\
\hline Transcription antitermination factor & spr1820 & G38T W13L & & \\
\hline ABC transporter ATP-binding/membrane-spanning protein & spr1885 & T490G S164R & & \\
\hline ABC transporter ATP-binding/membrane-spanning protein & spr1887 & G-32T & & \\
\hline
\end{tabular}

${ }^{a}$ The S. pneumoniae loci number (spr\#) are according to the annotation of S. pneumoniae R6.

${ }^{b}$ When the mutations are within coding regions, the change in amino acids is also indicated in italics.

' In noncoding sequences, the number preceded by '-' indicates the position upstream of the ATG.

d DNA of mutant 1974M1 transformed into 1974 (T3 represents third level transformation).

e DNA of mutant 1974M1 transformed into R6 (T2 represents second level transformation). 
Table 3 Relationship between the mutation status at domain V of every 235 rRNA gene and the level of resistance to linezolid and other antibiotics.

\begin{tabular}{|c|c|c|c|c|c|c|c|c|c|c|}
\hline $\begin{array}{l}\text { S. pneumoniae } \\
\text { strains }\end{array}$ & $\begin{array}{l}235 \text { rDNA status in PCR } \\
\text { fragment/transformant }\end{array}$ & $\begin{array}{l}\text { No. of } \\
\text { colonies } \\
\text { tested }\end{array}$ & ${ }_{\text {rrnaD }}^{\text {spr }}$ & $\underset{\text { rrnaC }}{\text { spr }_{-}}$ & spr $_{\text {rnaB }}$ & $\underset{\text { rrnaA }}{\text { spr }_{-}}$ & $\begin{array}{c}\text { MIC } \\
\text { LNZ } \\
(\mu \mathrm{g} / \\
\mathrm{ml})\end{array}$ & $\begin{array}{l}\mathrm{MIC} \\
\mathrm{CHL} \\
(\mu \mathrm{g} / \\
\mathrm{ml})\end{array}$ & $\begin{array}{l}\text { MIC FFC } \\
(\mu \mathrm{g} / \mathrm{ml})\end{array}$ & $\begin{array}{l}\text { MIC PCG } \\
(\mu \mathrm{g} / \mathrm{ml})\end{array}$ \\
\hline $\mathrm{R6}$ & & 4 & W & W & W & W & 0.5 & 3 & 1 & 0.023 \\
\hline T-R6 ${ }^{23 S r D N A R 6 M 2}$ & G2576T/G2576T & 3 & $M$ & W & W & W & 1 & 6 & 2 & 0.023 \\
\hline T-R6 ${ }^{23 S r D N A R 6 M 2}$ & G2576T/G2576T & 4 & M & W & W & M & 2 & 12 & 2 & 0.023 \\
\hline T-R6 $6^{23 S r D N A R 6 M 2}$ & G2576T/G2576T & 4 & $M$ & $M$ & W & M & 4 & 16 & 8 & 0.023 \\
\hline T-R6 23 SrDNAR6M2 & G2576T/G2576T & 4 & M & M & M & M & 8 & 24 & 16 & 0.023 \\
\hline 1974 & & 4 & W & W & W & W & 1 & 3 & 2 & 0.023 \\
\hline $\begin{array}{l}\text { T- } \\
1974^{23 S r D N A 1974 M 1}\end{array}$ & G2576T/G2576T & 12 & $M$ & $M$ & $M$ & M & 16 & 24 & 16 & 0.023 \\
\hline
\end{tabular}

W (wild-type version); M (1974M1 version); LNZ (linezolid); CHL (chloramphenicol); FFC (florfenicol); PCG (penicillin G).

cassette $(\mathrm{ABC})$ genes spr1887 and spr1021 (Table 2, Figure 1). Of these, only the $23 \mathrm{~S}$ rRNA and spr1021 mutations were transferred to R6T2 and/or $1974 \mathrm{~T} 3$ (Table $2)$. When the mutations in or upstream of spr0333, spr1021 or spr1887 were specifically transformed into WT backgrounds of S. pneumoniae R6 (data not shown) or S. pneumoniae 1974 (Table 4), only the mutation upstream of spr1021 was able to increase LNZ resistance and this was correlated with its overexpression (Table 5). Similarly to sensitive isolates, only the mutation linked to spr1021 changed the LNZ susceptibility values when transformed into the T-7 cells (Table 4).
The acquisition of LNZ resistance conferred a growth defect to the 1974M1 mutant $(p<0.01)$ (Figure 2A, B) and growth kinetic experiments revealed that this was due to several mutations associated with resistance to LNZ. Indeed, the growth of the T-7 transformant harboring four altered copies of $23 \mathrm{~S}$ rRNA was retarded compared to its 1974 parent $(p<0.01)$, even when compared to the 1974M1 mutant $(p<0.01)$ (Figure 2A). This growth defect was further enhanced by the mutation located within the rRNA methytransferase $\operatorname{spr} 0333(p<0.01)$ and by the mutation leading to the overexpression of the $\mathrm{ABC}$ gene spr1021 (Figure 2A). The fitness cost conferred by these

Table 4 Functional analysis of mutations in genes spr0188, spr0196, spr0333, spr1021 and spr1887 in resistance to LNZ and other antibiotics in S. pneumoniae.

\begin{tabular}{|c|c|c|c|c|c|c|c|}
\hline $\begin{array}{l}\text { Strains/ } \\
\text { transformants }^{a}\end{array}$ & Locus $^{b}$ & $\begin{array}{l}\text { No. of colonies } \\
\text { tested }\end{array}$ & $\begin{array}{c}\text { Mutation status } \\
1974 \mathrm{M} 1^{\mathrm{c}, \mathrm{d}}\end{array}$ & $\begin{array}{l}\text { Mutation status } \\
\text { Transformants }\end{array}$ & $\begin{array}{c}\text { MIC } \\
\text { LNZ }^{\mathrm{e}} \\
(\mu \mathrm{g} / \mathrm{ml})\end{array}$ & $\begin{array}{c}\mathrm{MIC} \\
\mathrm{CHL}^{\mathrm{e}} \\
(\mu \mathrm{g} / \mathrm{ml})\end{array}$ & $\begin{array}{c}\mathrm{MIC} \\
\mathrm{FFC}^{\mathrm{e}} \\
(\mu \mathrm{g} / \mathrm{ml})\end{array}$ \\
\hline R6 & & & & & 0.5 & 3 & 2 \\
\hline T-R6 ${ }^{\text {spro188 }}$ & spr0188 & 8 & A409G Y137H & A409G Y137H & 0.5 & 3 & 3 \\
\hline T-R6 ${ }^{\text {spr0196 }}$ & spr0196 & 8 & T235G I79L & T235G I79L & 0.5 & 3 & 2 \\
\hline T-R6 ${ }^{\text {spr1887 }}$ & spr1887 & 8 & G-46T & G-46T & 0.5 & 3 & 2 \\
\hline 1974 & & & & & 1 & 3 & 2 \\
\hline T-1974 $4^{\text {spr0333 }}$ & spr0333 & 8 & G626T G209V & G626T G209V & 1 & 4 & 4 \\
\hline T-1974 $4^{\text {spr1021 }}$ & spr1021 & 3 & G-29T & G-29T & 2 & 4 & 4 \\
\hline $\begin{array}{l}\text { T-1974 23SrDNA1974M1 } \\
\text { (T-7) }\end{array}$ & spr_rrnaDCBA23S & & G2576T & G2576T & 16 & 24 & 16 \\
\hline $\mathrm{T}-7^{\text {spro333 }}$ & spr0333 & 4 & G626T G209V & G626T G209V & 16 & 24 & 16 \\
\hline $\mathrm{T}-7^{\text {spr1021 }}$ & spr1021 & 2 & G-29T & G-29T & 32 & 32 & 32 \\
\hline $\mathrm{T}-7^{\text {spr1887 }}$ & spr1887 & 4 & G-46T & G-46T & 16 & 24 & 16 \\
\hline $\mathrm{T}-7^{\mathrm{sp} 0188}$ & spr0188 & 4 & A409G Y137H & A409G Y137H & 16 & 24 & 16 \\
\hline \multirow[t]{2}{*}{ T-7sp0188, spro196 } & spr0188 & & A409G Y137H & A409G Y137H & 32 & 12 & 8 \\
\hline & spr0196 & & T235G I79L & T235G I79L & & & \\
\hline
\end{tabular}

${ }^{a}$ T stands for transformants; spr0188 (ribosomal protein L3); spr0196 (ribosomal protein L16); spr0333 (conserved hypothetical protein/rRNA methyltransferase) spr1021 (ABC protein-coding gene); spr1887 (patA ABC gene).

${ }^{\mathrm{b}}$ The $S$. pneumoniae loci number (spr\#) are according to the nomenclature of S. pneumoniae R6.

' In noncoding sequences, the number preceded by '-' indicates the position upstream of the ATG.

${ }^{d}$ When the mutations are within coding regions, the changes in amino acids is indicated in italics.

e LNZ (linezolid); CHL (chloramphenicol); FFC (florfenicol). 


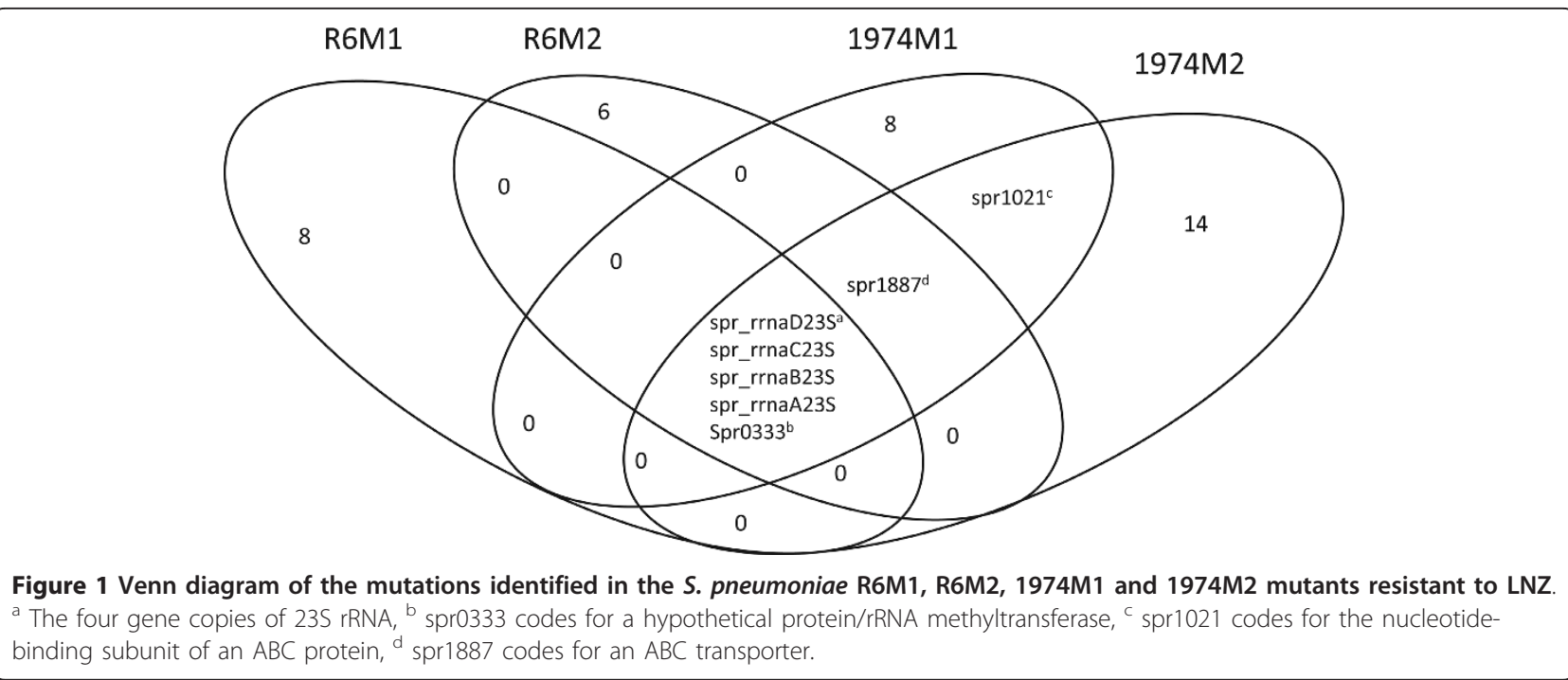

last two mutations required a background of altered 23S rRNA however, as their transformation failed to affect the growth of S. pneumoniae 1974 WT (data not shown). In contrast, we found that most 1974M1 mutations that could not be directly linked to LNZ resistance by transformation experiments or the mutations that failed to be transferred to the R6T2 and 1974T3 transformants acted as compensatory mutations involved in increasing the growth fitness of the 1974M1 mutant. Notably, the mutations in the genes coding for the ribosomal protein L3 (Figure 2B) and the mutation leading to the overexpression of the $A B C$ gene spr1887 (Table 5 and Figure 2A) were able to compensate in part for the fitness cost associated with altered copies of $23 \mathrm{~S}$ rRNA $(p<0.01)$. The mutation upstream of spr1887 was further able to compensate the growth defect conferred by the mutation of the RNA methyltransferase spr0333 and by the overexpression of the $\mathrm{ABC}$ gene spr1021 $(p<0.01)$ (Figure 2A). Mutations can thus be involved in either resistance, fitness compensation, or both.

\section{Discussion}

LNZ is a member of the oxazolidinone class of antibiotics that inhibit translation initiation by targeting the domain $\mathrm{V}$ of the $23 \mathrm{~S}$ rRNA. Although resistance to LNZ in clinical settings is rare, and so far absent in the case of $S$. pneumoniae [3,5], the analysis of LNZ-resistant strains revealed the $23 \mathrm{~S}$ rRNA G2576T mutation to be a major resistance determinant. Other mutations can still be implicated in resistance however, as described in LNZ-resistant Enterococci, Staphylococci and S. pneumoniae $[21,22,26,29,36]$. Recent advances in DNA sequencing technology make possible the study at the wholegenome level of the genetic bases implicated in the mode of action and resistance mechanisms of drugs [37-42]. To pinpoint the mutations most relevant to LNZ resistance, we sequenced a new $S$. pneumoniae strain, 1974M1, and two S. pneumoniae LNZ-resistant transformants generated by whole genome serial transformation of LNZ-sensitive strains with genomic DNA isolated from highly LNZ-resistant mutants.

We first concentrated on recurrent mutations transferred to both transformants as we hypothesized that these would be the most likely to be responsible for resistance. As reported in other bacterial species $[22,26,27,29]$, the G2576T $23 \mathrm{~S}$ rRNA mutation is also key for LNZ resistance in S. pneumoniae. Similarly to

Table 5 qRT-PCR to monitor gene expression after introducing a point mutation upstream of spr1021 (G-29T) and spr1887 (G-46T) in the S. pneumoniae 1974 and T-7 lines.

\begin{tabular}{|c|c|c|}
\hline Strains/transformants & $\begin{array}{c}\text { Mean 1974T/1974WT } \\
\text { spr1021 expression ratio a, b, c }\end{array}$ & $\begin{array}{c}\text { Mean 1974T/1974WT } \\
\text { spr1887 expression } \text { ratio }^{a, b} \text {, c }\end{array}$ \\
\hline T-1974 ${ }^{\text {spr1021 }}$ & $3.6(0.4)$ & $1.2(0.2)$ \\
\hline $\mathrm{T}-7^{\text {spr1021 }}$ & $3.4(0.4)$ & $1.2(0.2)$ \\
\hline $\mathrm{T}-7^{\text {spr1021, spr1887 }}$ & $3.3(0.5)$ & $12.9(0.2)$ \\
\hline 1974 & $1(0.2)$ & $1(0.2)$ \\
\hline
\end{tabular}

${ }^{\mathrm{a}} \mathrm{T}$ (transformant); WT (wild-type)

${ }^{\text {b } V a l u e s ~ r e p r e s e n t ~ a n ~ a v e r a g e ~ o f ~ t h r e e ~ i n d e p e n d e n t ~ e x p e r i m e n t s . ~}$

${ }^{\mathrm{C}}$ The standard deviation is indicated in parentheses. 


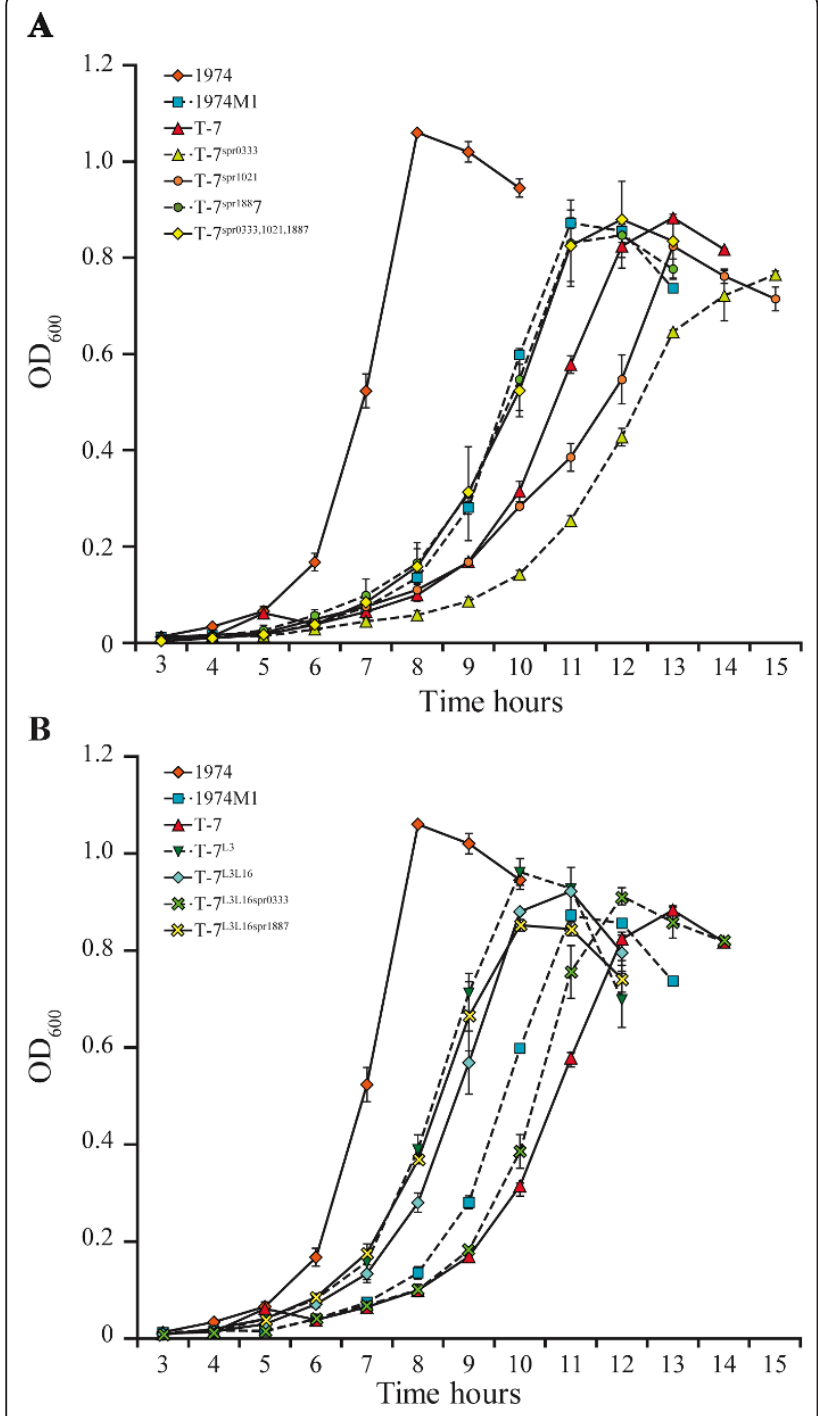

Figure 2 Growth kinetics of S. pneumoniae wild-type (1974), LNZ-resistant mutant (1974M1) and LNZ-resistant

transformants. A. Growth curves of S. pneumoniae 1974 transformed with four mutated copies of 235 rRNA alone (T-7); or along with altered versions of spr0333 (T-7 $\left.7^{\text {spro333 }}\right)$; spr1021 (T$\left.7^{\text {spr1021 }}\right)$; spr1887 (T-7 $\left.{ }^{\text {spr1887 }}\right)$; or a combination of the three (T$7^{\text {spro333, 1021, 1887) }}$. B. Growth curves of S. pneumoniae 1974 transformed with four mutated copies of $23 \mathrm{~S}$ rRNA alone (T-7); or along with altered versions of spr0188 (T- $\left.7^{L 3}\right)$; spr0188 and spr0196

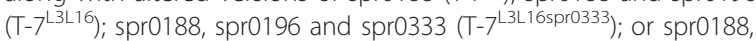

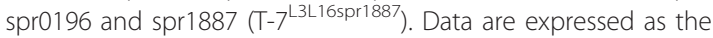
mean of three independent experiments and the statistical significance of the growth differences are indicated in the text.

Staphylococcus and Enterococci [12,21,22,26,36], the level of resistance to LNZ in S. pneumoniae R6 correlates with the number of mutated gene copies of $23 \mathrm{~S}$ rRNA. The same gene dosage effect was also observed for the level of cross-resistance to chloramphenicol and florfenicol, two other translation inhibitors acting at the level of domain V of $23 S$ rRNA [43]. In S. pneumoniae 1974, the four mutated copies were always simultaneously acquired during the targeted transformation of $23 \mathrm{~S}$ rRNA PCR fragments (12 colonies analyzed). Whether this is due to strain-specific features remains to be established.

The acquisition of 23S rRNA G2576T mutations conferred a biological cost to the S. pneumoniae 1974M1 mutant (Figure 2). Reduced fitness is a frequent outcome associated with antibiotic resistance [44] and the acquisition of mutations in the primary targets of fluoroquinolones $(\operatorname{gyr} A)[45,46]$ and $\beta$-lactams (penicillinbinding proteins) $[47,48]$ were also shown to confer a growth defect in S. pneumoniae resistant mutants. Compensatory mutations occurring either within the genes responsible for resistance or at distinct sites were shown to increase the fitness of the resistant strains, and can even help in achieving higher levels of resistance [49]. Mutations in 50S ribosomal proteins have been observed in LNZ-resistant strains of S. pneumoniae and S. aureus $[10,27,28,50-52]$ and the selection of a Y137H mutation in the L3 ribosomal protein (spr0188) of 1974M1 is consistent with the reduced LNZ susceptibility previously reported to be conferred by the F147L mutation in ribosomal protein L3 of S. epidermidis (which corresponds to amino acid 137 in S. pneumoniae) [51]. This mutation failed to directly translate into enhanced levels of LNZ resistance when transferred into R6 WT cells (Table 4) however, although it seems to be implicated in resistance when L16 is mutated and in a context where 23S rRNA is mutated at position G2576T (Table 4). In addition, these mutations are also able to compensate for the growth defect conferred by the $23 \mathrm{~S}$ rRNA G2576T mutation (Figure 2). Crystallographic studies of the $50 \mathrm{~S}$ ribosomal subunit have shown that several ribosomal proteins contain extensions approaching $23 \mathrm{~S}$ rRNA bases near the peptidyltransferase center (PTC), and a critical subset of these proteins includes the L3 and L16 proteins $[53,54]$. Although they are not part of the PTC per se, mutations at residues close to the PTC in L3 and L16 ribosomal proteins could still be implicated in releasing constraints associated with the acquisition of the unfavorable G2576T 23S rRNA mutation by altering the conformation and/or stability of the PTC through changes in second- and third-shell interactions. This could explain the frequent acquisition of ribosomal protein mutations following selection of resistance to LNZ in different bacterial species [3]. The L3 and L16 mutation together conferred increased sensitivity to chloramphenicol and florfenicol however (Table 4), which could be explained by distinct $23 \mathrm{~S}$ rRNA binding sites compared to LNZ [55].

The selection of a single nucleotide mutation leading to the overexpression of the $\mathrm{ABC}$ protein spr 1887 (Table 5) in S. pneumoniae LNZ-resistant mutants was 
shown to confer a small but significant increase in the level of resistance to LNZ [29]. Interestingly, we showed here that the increased expression of spr1887 was also able to compensate for the fitness cost conferred by a number of LNZ resistance determinants, including major resistance mechanisms like mutations in $23 \mathrm{~S}$ rRNAs and more specific ones like mutations in the rRNA methyltransferase spr0333 (Figure 2). The genome of S. pneumoniae encodes several ABC proteins, some of which were shown to be involved in drug resistance [56-58]. As mutations at the primary target site (23S rRNA) may lead to excessive concentrations of free LNZ, the cell might require to increase the expression of $\mathrm{ABC}$ efflux systems like spr1887 [56,57] to expel the excess of LNZ. Indeed, the decay of antibiotics was shown to generate degradation products displaying potential biological activities and to be detrimental to the strains having acquired primary resistance determinants [59].

\section{Conclusions}

The parent mutants had more mutations than the transformants (Table 1), which suggests that long term stepby-step selection and growth may require additional mutations or that spurious neutral changes are occurring during the selection of resistance. The mutations identified here fully account for the level of LNZ resistance of the mutant and some were found to compensate for a fitness cost. The combination of whole genome transformation and sequencing used here was useful for highlighting mutations playing a dual role in LNZ resistance and fitness compensation.

\section{Methods \\ Bacterial strains, growth conditions and MIC determinations}

The R6M1, R6M2, 1974M1 and 1974M2 LNZ-resistant mutants have respectively been generated from the avirulent S. pneumoniae strain R6 and the serotype 14 S. pneumoniae clinical isolates CCRI-1974 as described previously [29]. The genome sequence of these strains was available which facilitated our approach of whole genome transformation and sequencing. Transformants are described in Tables 1, 2, 3 and 4. Pneumococci were grown in brain heart infusion broth (BHI, Difco) supplemented with $0.5 \%$ yeast extract, or in blood agar containing 5\% defibrinated sheep's blood. Cultures were incubated for 16-24 hours in a $5 \% \mathrm{CO}_{2}$ atmosphere at $37^{\circ} \mathrm{C}$. The minimal inhibitory concentration (MIC) of drugs was determined by E-test (AB Biodisk) or microdilution. The microdilution assays were performed according to the guidelines of the Clinical and Laboratory Standards Institute (CLSI). The MIC was recorded as the lowest dilution showing no growth. All MIC measurements were done at least in triplicate.

\section{High molecular weight DNA transformation}

High molecular weight genomic DNA was extracted from the LNZ-resistant 1974M1 mutant using the Wizard Genomic DNA Purification Kit (Promega) according to the manufacturer's instructions. All pneumococci strains were made competent as follows. Bacteria were cultured at $37^{\circ} \mathrm{C}$ in $\mathrm{C}+\mathrm{Y}$ medium pH6.8 [60] until an optical density at $600 \mathrm{~nm}\left(\mathrm{OD}_{600}\right)$ of 0.12 . The cells were then concentrated tenfold and resuspended in $\mathrm{C}+\mathrm{Y}$ media ( $\mathrm{pH} 7.9$ ) with $10 \%$ glycerol and frozen at $-80^{\circ} \mathrm{C}$ in $100 \mu \mathrm{l}$ aliquots. For transformation experiments, the cells were thawed on ice and resuspended in 9 volumes of $\mathrm{C}+\mathrm{Y}$ media ( $\mathrm{pH}$ 7.9). The cells were stimulated with $200 \mathrm{ng} / \mathrm{ml}$ of competence stimulating peptide- 1 at $37^{\circ} \mathrm{C}$ for 10 minutes. The stimulated competent cells were exposed to approximately $2 \mu \mathrm{g} / \mathrm{ml}$ genomic DNA and incubated at $30^{\circ} \mathrm{C}$ for 1 hour, followed by 2 hours at $37^{\circ} \mathrm{C}$. One-hundred microliters of stimulated cells were then plated on CAT agar supplemented with $5 \%$ sheep blood and the appropriate concentration of LNZ.

\section{Whole-genome sequencing}

Genomic DNAs were prepared from mid-log phase cultures of S. pneumoniae strains using the Wizard Genomic DNA Purification Kit (Promega) according to the manufacturer's instructions. The genomes of the $1974 \mathrm{M} 1$ mutant and the $1974 \mathrm{~T} 3$ and R6T2 transformants were sequenced using the massively parallel sequencing 454 Life Sciences GS-FLX systems (Roche). Genome sequencing, assemblies and comparative analyses were performed at the McGill University Genome Quebec Innovation Center (http://gqinnovationcenter. com/index.aspx). The R6T2 and 1974T3 sequences produced an assembly of $22 \times$ and $23 \times$ coverage and an aggregate genome size of 2025687 bp and 1995497 bp, respectively. Whenever possible, the order and orientation of assembled contigs was done in accordance with the genome assembly of S. pneumoniae R6 (accession number NC_003098). Mutations deduced from massively parallel sequencing were confirmed by PCR amplification and conventional DNA sequencing. The sequencing data has been deposited at the NCBI under the accession [BioProject: 73475].

\section{RNA isolation and qRT-PCR}

Total RNA was isolated from bacterial cells grown to mid-log phase in BHI using the Qiagen RNeasy Mini Kit (Qiagen) according to the manufacturer's instructions. Genomic DNA contamination was shunned by digesting samples with DNase I (Ambion). The quality and integrity of the starting RNA material were assessed with a 2100 BioAnalyzer and RNA 6000 Nano chips (Agilent). The quality of the RNA was further 
determined by amplification of housekeeping gene. The cDNAs were generated from total RNAs using the Superscript II reverse transcriptase (Invitrogen) and random hexamers according to the manufacturer's instruction. Real-time quantitative RT-PCR assays were carried out in a BioRad Cycler using SYBR Green I (Molecular Probes). The reactions were carried out in a final volume of $20 \mu \mathrm{l}$ containing specific primers and $\mathrm{iQ}$ SYBR Green Supermix (Bio-Rad). All real-time qRTPCR data were normalized according to the amplification signals of the $16 \mathrm{~S}$ rRNA.

\section{Growth curves and fitness cost determination}

The turbidity of S. pneumoniae strains grown on blood agar plates was adjusted to $0.5 \mathrm{McF}$ arland units. For each strain, a $1 \mathrm{ml}$ aliquot of $0.5 \mathrm{McF}$ arland suspension was inoculated into $99 \mathrm{ml}$ of BHI broth and incubated at $37^{\circ} \mathrm{C}$ under a $5 \% \mathrm{CO}_{2}$ atmosphere. Bacterial growth was monitored by recording the $\mathrm{OD}_{600}$ at intervals of 1 hour for a total period of 16 hours. Differences in growth rates were measured by Analysis of Variance for statistical significance using the prism software.

\section{Additional material}

Additional file 1: Whole genome transformation and resistance reconstruction in Streptococcus pneumoniae. Figure S1 is a figure describing the strategy to reconstruct resistance to LNZ by using serial whole genome transformation in S. pneumoniae R6 and 1974

\section{List of abbreviations}

bp: base pair; LNZ: linezolid; MIC: minimum inhibitory concentration; rRNA: ribosomal ribonucleic acid; WT: wild-type

\section{Acknowledgements}

This work was funded by a CIHR grant to M.O. D.S.B received a postdoctoral fellowship of the CIHR/Rx\&D - Wyeth Pharmaceuticals Research Program. J.F. was a Strategic Training Fellow of the Strategic Training Program in Microbial Resistance, a partnership of the CIHR Institute of Infection and Immunity and the Fonds de Recherche en Santé du Québec. M.O. holds the Canada Research Chair in antimicrobial resistance. We thank the McGill University Genome Quebec Innovation Centre for performing the sequencing.

\section{Author details}

${ }^{1}$ Centre de recherche en Infectiologie du Centre de recherche du CHUL and Département de Microbiologie, Infectiologie et Immunologie, Faculté de Médecine, Université Laval, Québec, Canada. ${ }^{2}$ State Key Laboratory of Microbial Resources, Institute of Microbiology, Chinese Academy of Sciences, 1 West Beichen Road, Chaoyang District, Beijing 100101, China.

\section{Authors' contributions}

DSB, JF, DL and MO designed the study. DSB performed the experiments and drafted the manuscript. PL helped revise the manuscript and provided critical comments. All authors approved the final version of the manuscript for publication.

\section{Competing interests}

The authors declare that they have no competing interests.
Received: 10 August 2011 Accepted: 17 October 2011

Published: 17 October 2011

\section{References}

1. van Gils EJ, Veenhoven RH, Hak E, Rodenburg GD, Keijzers WC, Bogaert D, Trzcinski K, Bruin JP, van Alphen L, van der Ende, Sanders EA: Pneumococcal conjugate vaccination and nasopharyngeal acquisition of pneumococcal serotype 19A strains. Jama 304(10):1099-1106.

2. Farrell DJ, Mendes RE, Ross JE, Jones RN: Linezolid surveillance program results for 2008 (LEADER Program for 2008). Diagnostic microbiology and infectious disease 2009, 65(4):392-403.

3. Farrell DJ, Mendes RE, Ross JE, Sader HS, Jones RN: LEADER Program Results for 2009: an Activity and Spectrum Analysis of Linezolid Using 6,414 Clinical Isolates from 56 Medical Centers in the United States. Antimicrobial agents and chemotherapy 2011, 55(8):3684-3690.

4. Jones RN, Ross JE, Bell JM, Utsuki U, Fumiaki I, Kobayashi I, Turnidge JD: Zyvox Annual Appraisal of Potency and Spectrum program: linezolid surveillance program results for 2008. Diagnostic microbiology and infectious disease 2009, 65(4):404-413.

5. Zhanel GG, Adam HJ, Low DE, Blondeau J, Decorby M, Karlowsky JA Weshnoweski B, Vashisht R, Wierzbowski A, Hoban DJ: Antimicrobia susceptibility of 15,644 pathogens from Canadian hospitals: results of the CANWARD 2007-2009 study. Diagnostic microbiology and infectious disease 2011, 69(3):291-306.

6. Matassova NB, Rodnina MV, Endermann R, Kroll HP, Pleiss U, Wild H, Wintermeyer W: Ribosomal RNA is the target for oxazolidinones, a novel class of translational inhibitors. Rna 1999, 5(7):939-946.

7. Leach KL, Swaney SM, Colca JR, McDonald WG, Blinn JR, Thomasco LM, Gadwood RC, Shinabarger D, Xiong L, Mankin AS: The site of action of oxazolidinone antibiotics in living bacteria and in human mitochondria. Mol Cell 2007, 26(3):393-402

8. Wilson DN, Schluenzen F, Harms JM, Starosta AL, Connell SR, Fucini P: The oxazolidinone antibiotics perturb the ribosomal peptidyl-transferase center and effect tRNA positioning. Proc Natl Acad Sci USA 2008, 105(36):13339-13344

9. Vara Prasad JV: New oxazolidinones. Curr Opin Microbiol 2007, 10(5):454-460

10. Wolter N, Smith AM, Farrell DJ, Schaffner W, Moore M, Whitney CG, Jorgensen $J H$, Klugman KP: Novel mechanism of resistance to oxazolidinones, macrolides, and chloramphenicol in ribosomal protein L4 of the pneumococcus. Antimicrob Agents Chemother 2005, 49(8):3554-3557.

11. Mutnick AH, Enne V, Jones RN: Linezolid resistance since 2001: SENTRY Antimicrobial Surveillance Program. Ann Pharmacother 2003, 37(6):769-774

12. Prystowsky J, Siddiqui F, Chosay J, Shinabarger DL, Millichap J, Peterson LR, Noskin GA: Resistance to linezolid: characterization of mutations in rRNA and comparison of their occurrences in vancomycin-resistant enterococci. Antimicrob Agents Chemother 2001, 45(7):2154-2156.

13. Tsiodras S, Gold HS, Sakoulas G, Eliopoulos GM, Wennersten C, Venkataraman L, Moellering RC, Ferraro MJ: Linezolid resistance in a clinical isolate of Staphylococcus aureus. Lancet 2001, 358(9277):207-208

14. Meka VG, Gold HS: Antimicrobial resistance to linezolid. Clin Infect Dis 2004, 39(7):1010-1015.

15. Meka VG, Pillai SK, Sakoulas G, Wennersten C, Venkataraman L, DeGirolami PC, Eliopoulos GM, Moellering RC Jr, Gold HS: Linezolid resistance in sequential Staphylococcus aureus isolates associated with a T2500A mutation in the 23S rRNA gene and loss of a single copy of rRNA. J Infect Dis 2004, 190(2):311-317.

16. Hong T, Li X, Wang J, Sloan C, Cicogna C: Sequential linezolid-resistant Staphylococcus epidermidis isolates with G2576T mutation. J Clin Microbiol 2007, 45(10):3277-3280.

17. Kelly S, Collins J, Maguire M, Gowing C, Flanagan M, Donnelly M, Murphy PG: An outbreak of colonization with linezolid-resistant Staphylococcus epidermidis in an intensive therapy unit. J Antimicrob Chemother 2008, 61(4):901-907.

18. Bongiorno D, Campanile F, Mongelli G, Baldi MT, Provenzani R, Reali S, Lo Russo C, Santagati M, Stefani S: DNA methylase modifications and other linezolid resistance mutations in coagulase-negative staphylococci in Italy. J Antimicrob Chemother 65(11):2336-2340. 
19. Bourgeois-Nicolaos N, Piriou O, Butel MJ, Doucet-Populaire F: [Linezolid: antibacterial activity, clinical efficacy and resistance]. Ann Biol Clin (Paris) 2006, 64(6):549-564.

20. Gonzales RD, Schreckenberger PC, Graham MB, Kelkar S, DenBesten K, Quinn JP: Infections due to vancomycin-resistant Enterococcus faecium resistant to linezolid. Lancet 2001, 357(9263):1179.

21. Sinclair A, Arnold C, Woodford N: Rapid detection and estimation by pyrosequencing of 23S rRNA genes with a single nucleotide polymorphism conferring linezolid resistance in Enterococci. Antimicrob Agents Chemother 2003, 47(11):3620-3622.

22. Marshall SH, Donskey CJ, Hutton-Thomas R, Salata RA, Rice LB: Gene dosage and linezolid resistance in Enterococcus faecium and Enterococcus faecalis. Antimicrob Agents Chemother 2002, 46(10):3334-3336.

23. Ruggero KA, Schroeder LK, Schreckenberger PC, Mankin AS, Quinn JP: Nosocomial superinfections due to linezolid-resistant Enterococcus faecalis: evidence for a gene dosage effect on linezolid MICs. Diagn Microbiol Infect Dis 2003, 47(3):511-513.

24. Wilson P, Andrews JA, Charlesworth R, Walesby R, Singer M, Farrell DJ, Robbins M: Linezolid resistance in clinical isolates of Staphylococcus aureus. J Antimicrob Chemother 2003, 51(1):186-188.

25. Tsakris A, Pillai SK, Gold HS, Thauvin-Eliopoulos C, Venkataraman L, Wennersten C, Moellering RC Jr, Eliopoulos GM: Persistence of rRNA operon mutated copies and rapid re-emergence of linezolid resistance in Staphylococcus aureus. J Antimicrob Chemother 2007, 60(3):649-651.

26. Besier S, Ludwig A, Zander J, Brade V, Wichelhaus TA: Linezolid resistance in Staphylococcus aureus: gene dosage effect, stability, fitness costs, and cross-resistances. Antimicrob Agents Chemother 2008, 52(4):1570-1572.

27. Locke JB, Hilgers $M$, Shaw KJ: Novel ribosomal mutations in Staphylococcus aureus strains identified through selection with the oxazolidinones linezolid and torezolid (TR-700). Antimicrob Agents Chemother 2009, 53(12):5265-5274.

28. Locke JB, Hilgers M, Shaw KJ: Mutations in ribosomal protein L3 are associated with oxazolidinone resistance in staphylococci of clinical origin. Antimicrob Agents Chemother 2009, 53(12):5275-5278.

29. Feng J, Lupien A, Gingras H, Wasserscheid J, Dewar K, Legare D, Ouellette M: Genome sequencing of linezolid-resistant Streptococcus pneumoniae mutants reveals novel mechanisms of resistance. Genome Res 2009, 19(7):1214-1223.

30. Holzel CS, Harms KS, Schwaiger K, Bauer J: Resistance to linezolid in a porcine Clostridium perfringens strain carrying a mutation in the rpID gene encoding the ribosomal protein L4. Antimicrob Agents Chemother 54(3):1351-1353

31. Farrell DJ, Morrissey I, Bakker S, Buckridge S, Felmingham D: In vitro activities of telithromycin, linezolid, and quinupristin-dalfopristin against Streptococcus pneumoniae with macrolide resistance due to ribosomal mutations. Antimicrob Agents Chemother 2004, 48(8):3169-3171.

32. Toh SM, Xiong L, Arias CA, Villegas MV, Lolans K, Quinn J, Mankin AS: Acquisition of a natural resistance gene renders a clinical strain of methicillin-resistant Staphylococcus aureus resistant to the synthetic antibiotic linezolid. Molecular microbiology 2007, 64(6):1506-1514.

33. Bonilla H, Huband MD, Seidel J, Schmidt H, Lescoe M, McCurdy SP, Lemmon MM, Brennan LA, Tait-Kamradt A, Puzniak L, Quinn JP: Multicity outbreak of linezolid-resistant Staphylococcus epidermidis associated with clonal spread of a cfr-containing strain. Clin Infect Dis 51(7):796-800.

34. Morales G, Picazo JJ, Baos E, Candel FJ, Arribi A, Pelaez B, Andrade R, de la Torre MA, Fereres J, Sanchez-Garcia M: Resistance to linezolid is mediated by the cfr gene in the first report of an outbreak of linezolid-resistant Staphylococcus aureus. Clin Infect Dis 50(6):821-825.

35. Sanchez Garcia M, De la Torre MA, Morales G, Pelaez B, Tolon MJ, Domingo S, Candel FJ, Andrade R, Arribi A, Garcia N, Martínez Sagasti F, Fereres J, Picazo J: Clinical outbreak of linezolid-resistant Staphylococcus aureus in an intensive care unit. Jama 303(22):2260-2264.

36. Livermore DM, Mushtaq S, Warner M, Woodford N: Activity of oxazolidinone TR-700 against linezolid-susceptible and -resistant staphylococci and enterococci. J Antimicrob Chemother 2009, 63(4):713-715

37. Albert TJ, Dailidiene D, Dailide G, Norton JE, Kalia A, Richmond TA, Molla M, Singh J, Green RD, Berg DE: Mutation discovery in bacterial genomes: metronidazole resistance in Helicobacter pylori. Nature methods 2005, 2(12):951-953.
38. Andries K, Verhasselt P, Guillemont J, Gohlmann HW, Neefs JM, Winkler H, Van Gestel J, Timmerman P, Zhu M, Lee E, Williams P, de Chaffoy D, Huitric E, Hoffner S, Cambau E, Truffot-Pernot C, Lounis N, Jarlier V: A diarylquinoline drug active on the ATP synthase of Mycobacterium tuberculosis. Science (New York, NY 2005, 307(5707):223-227.

39. Charusanti P, Conrad TM, Knight EM, Venkataraman K, Fong NL, Xie B, Gao Y, Palsson BO: Genetic basis of growth adaptation of Escherichia coli after deletion of pgi, a major metabolic gene. PLoS genetics 2010, 6(11): e1001186.

40. Gao W, Chua K, Davies JK, Newton HJ, Seemann T, Harrison PF, Holmes NE, Rhee HW, Hong Jl, Hartland EL, Stinear TP, Howden BP: Two novel point mutations in clinical Staphylococcus aureus reduce linezolid susceptibility and switch on the stringent response to promote persistent infection. PLoS pathogens 2010, 6(6):e1000944.

41. Manjunatha UH, Boshoff H, Dowd CS, Zhang L, Albert TJ, Norton JE, Daniels L, Dick T, Pang SS, Barry CE: Identification of a nitroimidazooxazine-specific protein involved in PA-824 resistance in Mycobacterium tuberculosis. Proceedings of the National Academy of Sciences of the United States of America 2006, 103(2):431-436.

42. Mwangi MM, Wu SW, Zhou Y, Sieradzki K, de Lencastre $H$, Richardson $P$, Bruce $D$, Rubin E, Myers E, Siggia ED, Tomasz A: Tracking the in vivo evolution of multidrug resistance in Staphylococcus aureus by wholegenome sequencing. Proceedings of the National Academy of Sciences of the United States of America 2007, 104(22):9451-9456.

43. Lin AH, Murray RW, Vidmar TJ, Marotti KR: The oxazolidinone eperezolid binds to the $50 \mathrm{~S}$ ribosomal subunit and competes with binding of chloramphenicol and lincomycin. Antimicrob Agents Chemother 1997 41(10):2127-2131.

44. Andersson DI: The biological cost of mutational antibiotic resistance: any practical conclusions? Curr Opin Microbiol 2006, 9(5):461-465.

45. Balsalobre $L$, de la Campa AG: Fitness of Streptococcus pneumoniae fluoroquinolone-resistant strains with topoisomerase IV recombinant genes. Antimicrob Agents Chemother 2008, 52(3):822-830.

46. Rozen DE, McGee L, Levin BR, Klugman KP: Fitness costs of fluoroquinolone resistance in Streptococcus pneumoniae. Antimicrob Agents Chemother 2007, 51(2):412-416.

47. Trzcinski K, Thompson CM, Gilbey AM, Dowson CG, Lipsitch M: Incremental increase in fitness cost with increased beta -lactam resistance in pneumococci evaluated by competition in an infant rat nasal colonization model. J Infect Dis 2006, 193(9):1296-1303.

48. Rieux V, Carbon C, Azoulay-Dupuis E: Complex relationship between acquisition of beta-lactam resistance and loss of virulence in Streptococcus pneumoniae. J Infect Dis 2001, 184(1):66-72.

49. Marcusson LL, Frimodt-Moller N, Hughes D: Interplay in the selection of fluoroquinolone resistance and bacterial fitness. PLoS Pathog 2009, 5(8): e1000541.

50. Biedenbach DJ, Farrell DJ, Mendes RE, Ross JE, Jones RN: Stability of linezolid activity in an era of mobile oxazolidinone resistance determinants: results from the 2009 Zyvox(R) Annual Appraisal of Potency and Spectrum program. Diagn Microbiol Infect Dis 68(4):459-467.

51. Mendes RE, Deshpande LM, Farrell DJ, Spanu T, Fadda G, Jones RN: Assessment of linezolid resistance mechanisms among Staphylococcus epidermidis causing bacteraemia in Rome, Italy. J Antimicrob Chemother 65(11):2329-2335.

52. Locke JB, Morales G, Hilgers M, G CK, Rahawi S, Jose Picazo J, Shaw KJ, Stein $J$ : Elevated linezolid resistance in clinical cfr-positive Staphylococcus aureus isolates is associated with co-occurring mutations in ribosomal protein L3. Antimicrob Agents Chemother 54(12):5352-5355.

53. Ban N, Nissen P, Hansen J, Moore PB, Steitz TA: The complete atomic structure of the large ribosomal subunit at 2.4 A resolution. Science 2000, 289(5481):905-920.

54. Harms J, Schluenzen F, Zarivach R, Bashan A, Gat S, Agmon I, Bartels H, Franceschi $F$, Yonath $A$ : High resolution structure of the large ribosomal subunit from a mesophilic eubacterium. Cell 2001, 107(5):679-688.

55. Kehrenberg C, Schwarz S, Jacobsen L, Hansen LH, Vester B: A new mechanism for chloramphenicol, florfenicol and clindamycin resistance: methylation of 23S ribosomal RNA at A2503. Mol Microbiol 2005, 57(4):1064-1073.

56. Robertson GT, Doyle TB, Lynch AS: Use of an efflux-deficient streptococcus pneumoniae strain panel to identify $A B C$-class multidrug 
transporters involved in intrinsic resistance to antimicrobial agents. Antimicrob Agents Chemother 2005, 49(11):4781-4783.

57. Marrer E, Schad K, Satoh AT, Page MG, Johnson MM, Piddock LJ: Involvement of the putative ATP-dependent efflux proteins PatA and PatB in fluoroquinolone resistance of a multidrug-resistant mutant of Streptococcus pneumoniae. Antimicrob Agents Chemother 2006, 50(2):685-693.

58. Garvey MI, Baylay AJ, Wong RL, Piddock LJ: Overexpression of patA and pat $B$, which encode $A B C$ transporters, is associated with fluoroquinolone resistance in clinical isolates of Streptococcus pneumoniae. Antimicrob Agents Chemother 55(1):190-196.

59. Palmer AC, Angelino E, Kishony R: Chemical decay of an antibiotic inverts selection for resistance. Nat Chem Biol 6(2):105-107.

60. Tomasz A, Hotchkiss RD: Regulation of the Transformability of Pheumococcal Cultures by Macromolecular Cell Products. Proc Natl Acad Sci USA 1964, 51:480-487.

doi:10.1186/1471-2164-12-512

Cite this article as: Billal et al:: Whole genome analysis of linezolid resistance in Streptococcus pneumoniae reveals resistance and compensatory mutations. BMC Genomics 2011 12:512.

\section{Submit your next manuscript to BioMed Central} and take full advantage of:

- Convenient online submission

- Thorough peer review

- No space constraints or color figure charges

- Immediate publication on acceptance

- Inclusion in PubMed, CAS, Scopus and Google Scholar

- Research which is freely available for redistribution

Submit your manuscript at www.biomedcentral.com/submit 